\title{
Factors Affecting the Adsorption of Some Ionic Dyes on the Surface of Modify $\mathrm{CaO}$ from Eggshell
}

\author{
Ibtighaa K. Radhi, Mouayed A. Hussein, Zaki N. Kadhim** \\ Department of Chemistry, College of Science, University of Basrah \\ Basrah, Iraq \\ *Corresponding author's emails: zekinasser99 [AT] yahoo.com
}

\begin{abstract}
In this paper, calcium oxide (CaO) was produced by the thermal treatment of eggshell. The doping process with silver iodide (AgI), oxygen $(O)$, sulfur(S) and nitrogen $(N)$ was achieved by adsorbents. The adsorption of Acid fuchsine (AF), Indigo Carmine (IC), Nigrosine (NG) and Alizarine Red S (AR) on the surface of these particles was studied. The different conditions affecting the adsorption process, such as the time of equilibrium, the primary concentration of the studied dyes, the amount of the adsorbent, the acidic function, the speed of the pruning motion and the temperature were studied. The pH stability time (5-10 minutes), IC and NG (30 minutes) and AR were (90 minutes). The effect of temperature was also studied within the range $\left(25-45^{\circ} \mathrm{C}\right)$. The results showed that the adsorption capacity increased by increasing the temperature, ie the reaction is endothermic. The study showed the effect of the acidic function on the percentage of pigmentation. The percentage was increased by increasing the acidic function in the basal circles on the surfaces except for the AR dye. It decreased the percentage by increasing the acidic function. The effect of the weight of the adsorbent was studied on the percentage of adsorption.
\end{abstract}

Keywords---- Adsorption, ionic dyes, eggshell, pH

\section{INTRODUCTION}

Adsorption can be defined as an attraction and accumulation gaseous or liquid substance in the form of molecules, leading to the formation of molecular (atoms or ions) layers on the surface of another solid material. The adsorbate is the substance in the adsorbed state and the substance to be adsorbed (before it is on the surface) is the adsorpt or adsorptive. The material onto which adsorption curry out is called the adsorbent [1].

Many factors affecting the adsorption process such as the nature of the adsorbent. The adsorption capacity depends on the characteristics of the surface, nature, chemical composition, surface area, as well as the distribution of the charge on the surface[2]. The catalyst has an important role in the adsorption process. The surface area is inversely proportional to the size of the particles. As a result, the lower the surface of the particles, the greater the number of active sites on the surface, increasing the adsorption capacity[3,4].

The important factors affecting the adsorption process is nature of adsorbate, the nature of adsorbate affects their physical properties, as adsorption increases by increasing the molecular weight of the absorbate material[5]. They are also affected by their chemical properties in of the existence of active groups in the composition of the absorbate material, and the capacity of adsorption increases by increasing the concentration of the absorbate material[6]

The initial concentration of adsorbate can be also influence the adsorption capacity of a certain weight of the adsorbent surface is increased by increasing the concentration of the absorbent material when the temperature is confirmed, but in some cases the adsorption may be limited to one layer of the adsorbent substance dissolved, so the increase in solute concentration may not increase adsorption due to network coverage Crystalline surface of the adsorbent surface[7]

The change in $\mathrm{pH}$ of the solution have an important effect on the process of adsorption of the solution, due to its effect on both the solvent and solvent surfaces. In the case of surfaces containing polarized or charged positions, the amount of adsorption increases if the surface acquires a charge that exceeds the charged minute charge through the effect of the acidic function, conversely, the amount of adsorption decreases if the surface and the absorbed minutes acquire a similar charge [8] In the case of the fact that $\mathrm{pH}$ the solution is low, the levels of adsorption of elements may be reduced due to the competition shown by ions $\left(\mathrm{H}^{+}\right)$for effective sites in the surface, in the case of a low solution, the levels of adsorption of elements may be reduced due to the competition of ions $\left(\mathrm{H}^{+}\right)\left(\mathrm{OH}^{-}\right)$the effect of the acidic function is shown by the competition of the solvent surface and the solvent and the solvent on the ions. As a result of this act negatively or positively affect the 
adsorption process and the behavior of adsorption isomerization, In the capacity and quantity of the substance absorbed on the surface from one composite to another[9].

The effect of temperature depends on the type of adsorption and the nature of both the absorbent and the adsorbate. The adsorption of the heat is increased by Exothermic process, in the Endothermic process the opposite is achieved. The adsorption increases with higher temperatures, where the kinetic energy of the adsorbed molecules increases and thus increases its ability to enter the solid phase pores And their rapid spread, and this may be within a specific range of temperatures[10,11].

In this study we were investigated some of factors affecting the adsorption process by using modified $\mathrm{CaO}$ isolated from hen's eggshell.

\section{EXPERIMENTAL}

\subsection{Materials and methods}

The materials for the preparation of AgI-doped $\mathrm{CaO}, \mathrm{AgI}$-doped $\mathrm{CaO}$ N-doped $\mathrm{CaO}$ and S-doped $\mathrm{CaO}$ were purchased from Sigma and Aldrich companies. $\mathrm{CaO}$ was used as a precursor for the doped $\mathrm{CaO}$ and adsorbent.

Dyes were supplied by Merck Co. without further purification. To prepare the stock solution, accurately weighed quantities of dyes were dissolved in distilled water in order to obtain other desired concentrations of solutions through successive dilutions.

\subsection{Adsorbent synthesis}

$\mathrm{AgI}-\mathrm{CaO}$ was prepared by dissolving a $1 \mathrm{~g}$ of $\mathrm{CaO}$ and $0.296 \mathrm{~g}$ of $\mathrm{KI}$ in $100 \mathrm{ml}$ of deionized water, then $0.303 \mathrm{~g}$ of $\mathrm{AgNO}_{3}$ in $2.3 \mathrm{ml}$ of $\mathrm{NH}_{4} \mathrm{OH}$ was rapidly added to this mixture, stirred at room temperature for 12 hours and dried at $70^{\circ}$ $\mathrm{C}$. The $\mathrm{O}$-doped $\mathrm{CaO}$ was prepared in the same way but using $10 \mathrm{~g} / \mathrm{L}$ mixed with a $5 \mathrm{~mL}$ ethanol and $0.1701 \mathrm{~g}$ urea origins for O-dopant. The powder was obtained after calcination at $400^{\circ} \mathrm{C}$ for $4 \mathrm{~h}$ in air. For S-dopant modification, $10 \mathrm{~g} / \mathrm{L}$ of $\mathrm{CaO}$ was placed in an conical flask with stirring for 15 minutes, then mixed with a $15 \mathrm{~mL}$ ethanol and $0.2714 \mathrm{~g}$ thiourea. $\mathrm{N}$-dopant modification a $10 \mathrm{~g} / \mathrm{L}$ of $\mathrm{CaO}$ was mixed with aqueous solution of $15 \mathrm{~mL}$ ethanol, $15 \mathrm{~mL}$ ammonia and $3 \mathrm{~mL}$ nitric acid as origins for $\mathrm{N}$-dopant organic nitrogen compound and stirred at room temperature for $12 \mathrm{~h}$. The mixture was dried at $80^{\circ} \mathrm{C}$ for $36 \mathrm{~h}$.

The X-ray powder diffraction (XRD) data was acquired using a PAN analytical X'Pert PRO Beta 1 diffractometer in

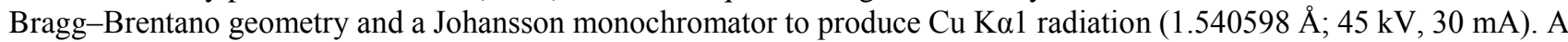
gently hand-ground powder sample was placed on silicon made zero-background holder using petrolatum jelly as an adhesive. The diffraction intensities were recorded from a spinning sample by an X'Celerator detector using continuous scanning mode in a $2 \theta$-range of $10-90^{\circ}$ with a step size of $0.017^{\circ}$

An S-4800 Ultra-High Resolution Scanning Electron Microscope (SEM) with a resolution of $1 \mathrm{~nm}$ was used to determine the surface composition of the samples. It was equipped with energy dispersive X-ray analysis (EDS) for determining chemical composition. The identificetion data published else where[12].

\subsection{Dyes}

The property of Acid Fuchsin, Indigo Carmin, Nigrosin and Alizarin red S show in table 1:

Table 1. Property of dyes

\begin{tabular}{lllll}
\hline Property & Acid Fuchsin & Indigo carmine & Nigrosine & Alizarin red S \\
\hline $\begin{array}{l}\text { Chemical } \\
\text { structure }\end{array}$ & & $\mathrm{C}_{16} \mathrm{H}_{8} \mathrm{~N}_{2} \mathrm{Na}_{2} \mathrm{O}_{8} \mathrm{~S}_{2}$ & $\mathrm{C}_{22} \mathrm{H}_{14} \mathrm{~N}_{6} \mathrm{O}_{9} \mathrm{~S}_{2}$ & $\mathrm{C}_{14} \mathrm{H}_{7} \mathrm{NaO}_{7} \mathrm{~S}$ \\
$\begin{array}{l}\text { Chemical } \\
\text { formula } \\
\begin{array}{l}\text { Moler mass } \\
(\text { g.mol }\end{array}\end{array}$ & $\mathrm{C}_{2} \mathrm{OH}_{17} \mathrm{~N}_{3} \mathrm{Na}_{2} \mathrm{O}_{9} \mathrm{~S}_{3}$ & 585.54 & 666.35 & 342.26 \\
\hline$\lambda$ max (nm) & $\mathbf{5 4 2 - 5 4 8 ( 5 6 9 )}$ & $\mathbf{6 0 8}(\mathbf{6 1 0})$ & $\mathbf{5 7 0 ( 5 7 3 )}$ & $\mathbf{5 2 0}$ \\
\hline
\end{tabular}




\subsection{Effect of Variable Parameters}

The equilibrium adsorption experiments were carried out to measure the efficiency of $\mathrm{CaO}$ in removing dyes in aqueous solution by chaining several factors, including the primary concentration of dyes, the amount of adsorbent, a cidic function $\mathrm{pH}$, mixing speed and temperature to find the best adsorption capacity and percentage of pigment. Adsorption tests were performed by study the adsorptive removal of dyes from aqueous solution by $\mathrm{CaO}$, where $25 \mathrm{~mL}$ of dyes solution of known initial concentration (40-120 mg/L of AF, 20-100 mg/L of IC, $10-50 \mathrm{mg} / \mathrm{L}$ of NG and $100-400 \mathrm{mg} / \mathrm{L}$ of AR) (C0), amount of the adsorbent $(0.001,0.005,0.01 \mathrm{~g}), \mathrm{pH}(4,7,9$ and 12) The $\mathrm{pH}$ values were adjusted by adding $0.1 \mathrm{~mol} / \mathrm{L} \mathrm{HCl}$ and 0.1 $\mathrm{mol} / \mathrm{L} \mathrm{NaOH}$ solutions and measured using a pH meter (inoLab pH-meter E-08328), mixing speed (100, 200, 300, 360 RPM) and temperature $(25,35,45 \mathrm{C})$, were taken in the $25 \mathrm{~mL}$ concal. The solution was then placed in Lab-Therm LabShaker control mixer and was shaken for (30 min of AF, 30min of IC, $30 \mathrm{~min}$ of $\mathrm{NG}$ and $90 \mathrm{~min}$ of AR) to ensure that adsorption process has reached equilibrium under. Next, the suspension was separated from aqueous solution centrifuged for doped-CaO and unmodified $\mathrm{CaO}$ particles. The equilibrium concentration $(\mathrm{Ce})$ of dyes was determined using an $\mathrm{UV} / \mathrm{Vis}$ spectrometer at ( 569, 610,573 and $520 \mathrm{~nm}$ ) (UV/VIS Spectrophotometry PG Instruments Limited, model ,T80 (EMCLAB). The adsorbed dye amounts were calculated from Eq. (1)

$q e=\frac{(\mathrm{Ce}-\mathrm{Co})}{m} V$

(qe) the amount of adsorbed dye per unit mass of adsorbents $(\mathrm{mg} / \mathrm{g})$ at equilibrium where Co and Ce are the initial and equilibrium concentrations of dyes, $\mathrm{m}$ is the adsorbent mass $(\mathrm{g})$ and $\mathrm{V}$ is the volume (ml) of the solution.

The removal percentage was calculated for each sample by the following equation:

$C \%=\frac{(C o-C t)}{C o} 100$

where $\mathrm{C}_{0}$ is the initial concentration of the samples.

Secondly, the prepared solutions were used for kinetic studies as explained in the kinetic experiments section above. The removal percentage was calculated for each sample by Eq. (2).

\section{RESULTS AND DISCUSSION}

\subsection{Effect of contact time and initial concentration of dye}

The initial dye concentration in solution plays a significant role as a driving force that overcomes mass transfer resistance of adsorbate between the solid phase and aqueous ${ }^{(13)}$. Figure 2,1 showed the equilibrium data are reveals that, adsorption ratio was decreased with increasing in initial concentration of dye, because of decreasing the number of free active sites on the surface at initial concentration of dye increases, so the amount of dye that can be removed decreases, but the actual amount of dye adsorbed per unit mass of adsorbent increased with increase in dye concentration. In the beginning, the molecules of the adsorbent must encounter the effect of the boundary layer, then they must spread from the boundary layer to the surface of the adsorbent, and eventually they should be spread to the porous structure of the adsorbent (14). Therefore, in the high concentration of dyes, the number of molecules competing on the available sites on the surface of the adsorbent is significant and occurred in high removal capacity of dyes. The relatively low concentration of dye to the site available on the surface is minimal and a high adsorption yield to be observed. It means that the adsorption is highly dependent on initial concentration of dye, because of that at lower concentration, the ratio of the initial number of dye molecules to the available surface area is low subsequently the fractional adsorption becomes independent of initial concentration. However, at high concentration the available sites of adsorption becomes fewer and hence the percentage removal of dye is dependent upon initial concentration ${ }^{(15,16)}$. The equilibrium attains at 10 minutes for Acid Fuchsin, 30 minutes for indigo Caramine and Nigrosine, 90 minutes for Alizarin Red S . 

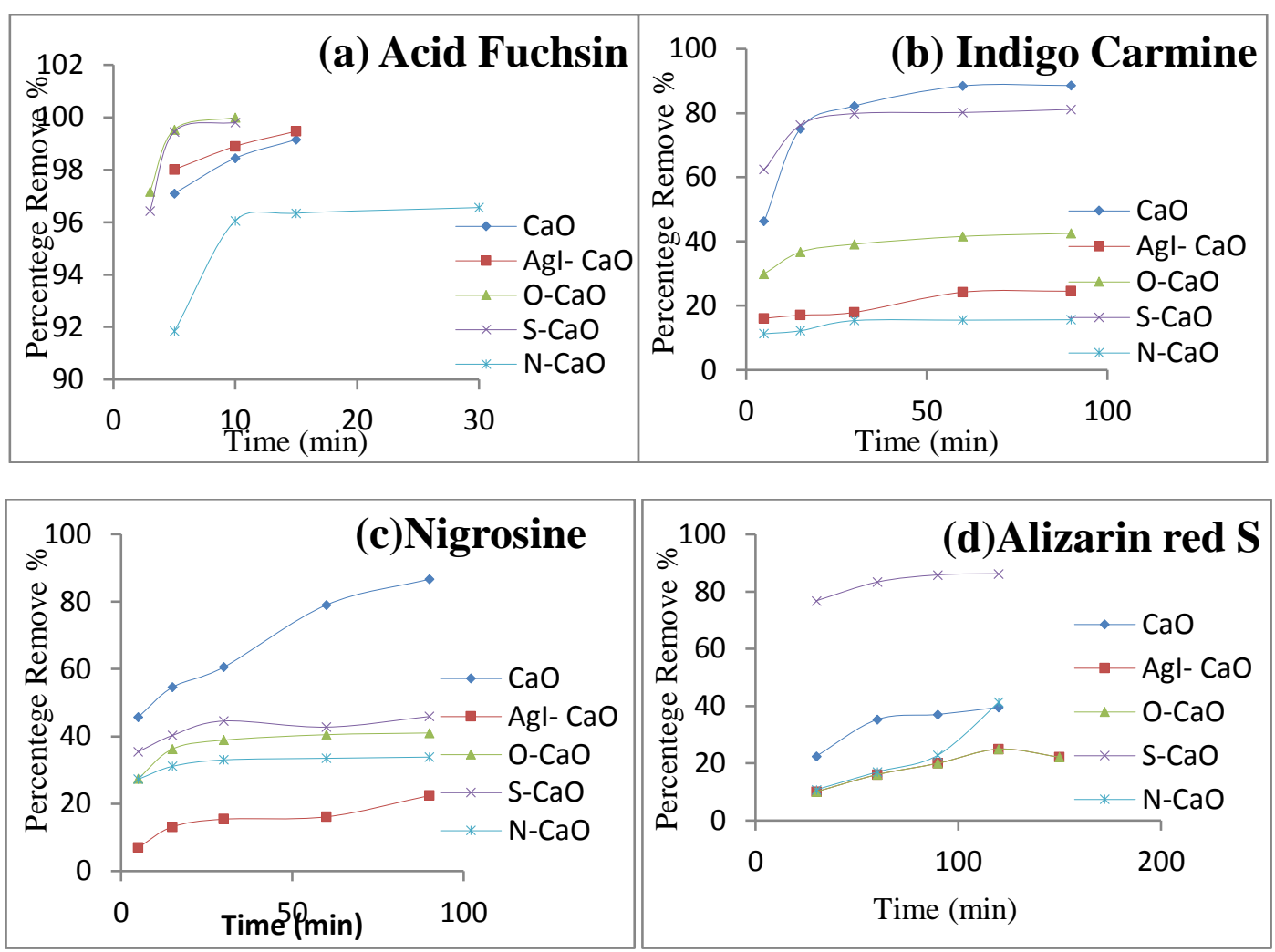

Figure 1: Effect of Contact Time on the Removal of (a)Acid Fuchsin (b) Indigo Carmine (c) Nigrosine and (d) Alizarin red $\mathrm{S}$ dye
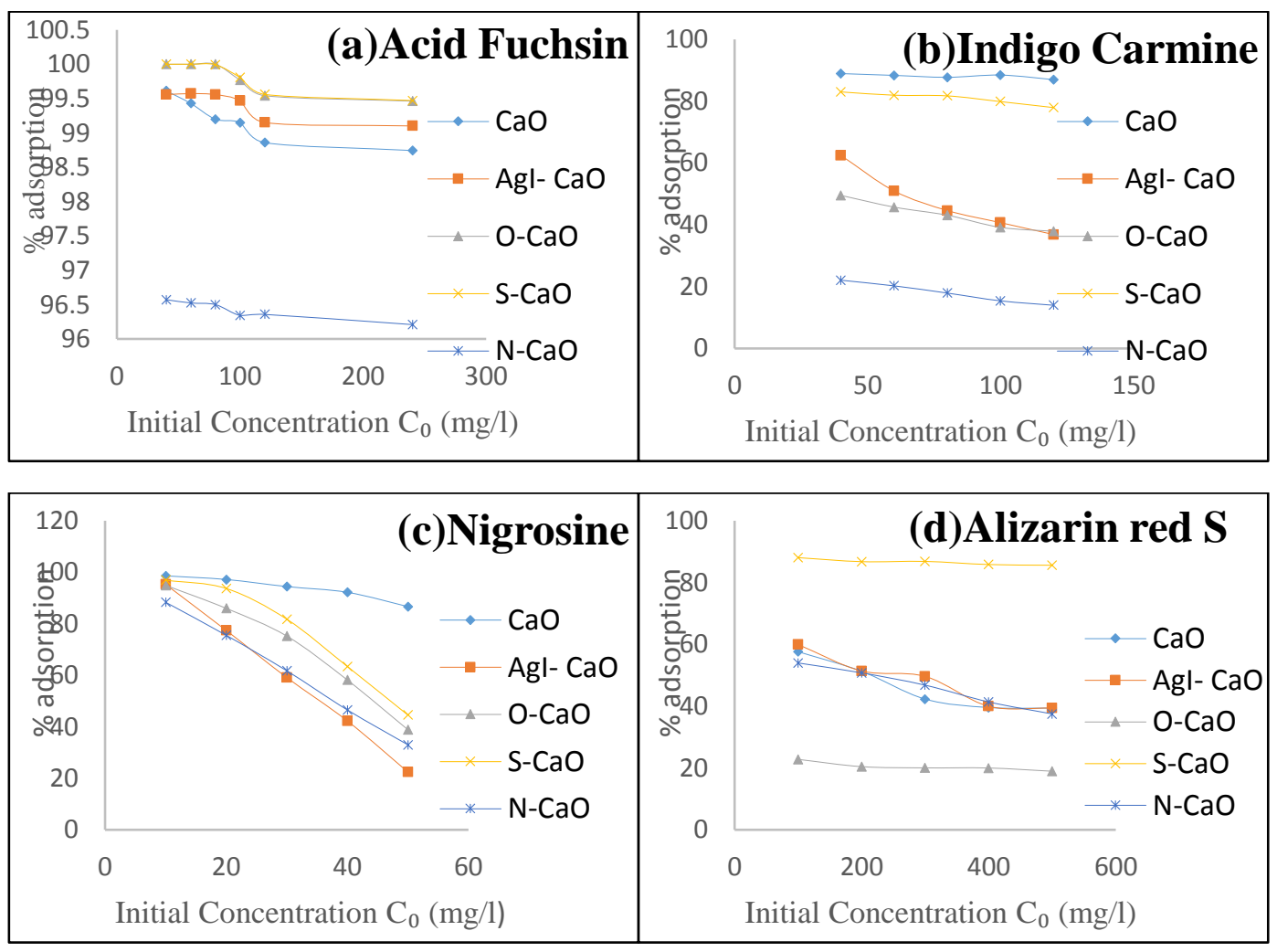

Figure 2: Relationship the percentage of removal for Initial Concentrations of (a)Acid Fuchsin (b) Indigo Carmine (c) Nigrosine and (d) Alizarin red S dye 


\subsection{Effect of $p H$}

Figure 3 shows that the $\mathrm{pH}$ of the medium plays a dominant role in the rate of dye adsorption. The amphoteric nature of $\mathrm{CaO}$ affects adsorption capacity ${ }^{(17,-19)}$, The high affinity of surface charge of the $\mathrm{CaO}$ for solution $\mathrm{pH}$ is worthy of investigation. It is suggested that at low $\mathrm{pH}$, the calcium surface is positively charged due to protonation of the surface hydroxyl group and it becomes negatively charged at high $\mathrm{pH}$ values. Beyond that, the isoelectric points can be used to qualitatively assess the adsorbent surface charge. Figure 3 shows the effect of $\mathrm{pH}$ on the adsorption of AF, IC, NG onto unmodified and modified $\mathrm{CaO}$ adsorbents. It can be seen that adsorption efficiency increased with the increase in $\mathrm{pH}$. Due to the amphoteric behavior of $\mathrm{CaO}$ on the solution $\mathrm{pH}$ and cationic character of dyes, therefore, the obtained higher uptake values at higher $\mathrm{pH}$ can be attributed to the electrostatic attraction between the positive charged cationic dye and the negatively charged $\mathrm{CaO}^{(17-20)}$. attraction between the positive charged cationic dye and the negatively charged $\mathrm{CaO}$.

AR dyes show a sorption drop off at high $\mathrm{pH}$ in Figure 3 because the dye contain an easily ionizable phenolic - $\mathrm{OH}$ group in the molecule. The presence of ionizable anionic groups like $\mathrm{OH}$ or $-\mathrm{COOH}$ in dye molecules might render decolourization less effective in alkaline textile wastewaters. But that $\mathrm{S}-\mathrm{CaO}$ demonstrates a different adsorbents in the acidic and alkaline $\mathrm{pH}$ value range (Figure 3). As can be seen, removal of AR by $\mathrm{S}-\mathrm{CaO}$ is highest at $\mathrm{pH} 12$. It is therefore suggested that the distinct trend of $\mathrm{S}-\mathrm{CaO}$ might be dependent on different phase composition. This is in agreement with the XRD analysis, which proved a different phase composition for S-CaO.
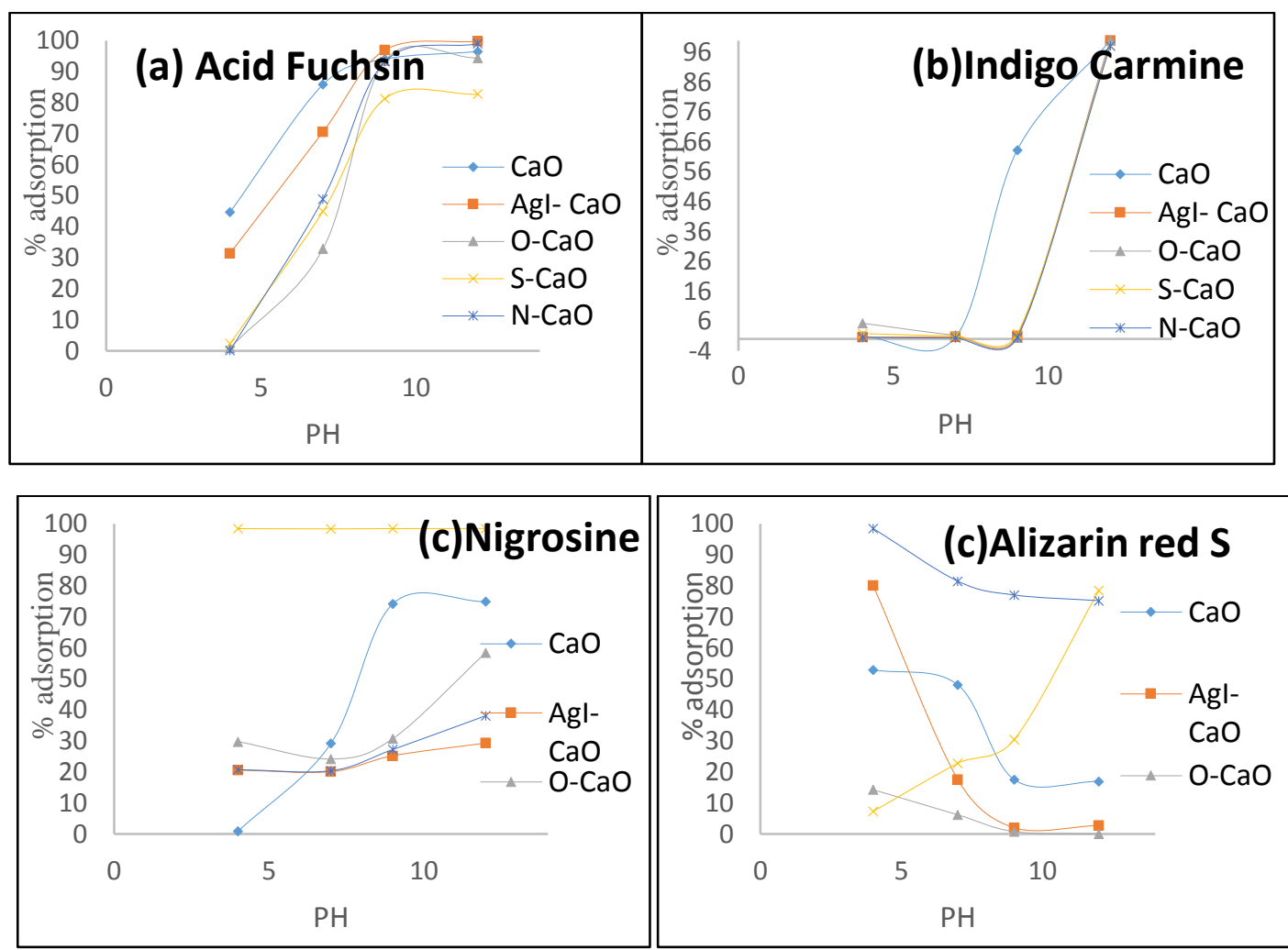

Figure 3: Relationship the Percentage of Removal for $\mathrm{pH}$ of (a)Acid Fuchsin (b) Indigo Carmine (c) Nigrosine and (d) Alizarin red S dye

\subsection{Adsorbent Weight}

The adsorption of the dyes onto the adsorbent was studied by varying the adsorbent dose $(0.005-0.05 \mathrm{~g} / 25 \mathrm{~mL})$ for 30 $\mathrm{mg} / \mathrm{L}$ of dye concentration $(25 \mathrm{ml}, 100 \mathrm{mg} / \mathrm{l})$ for Acid Fuchcin and Indigo Carmine, ( $25 \mathrm{ml}, 50 \mathrm{mg} / \mathrm{l})$ for the Nigrocine, $(25 \mathrm{ml}, 400 \mathrm{mg} / \mathrm{l})$ of Alizarin Red S,. The percentage of adsorption increased with increasing the dosage of the adsorbent (Figure 4). This was attributed to increased surface area and availability of more adsorption sites ${ }^{(15,16)}$.

Also, the results indicate that the increase in the percentage of removal is offset by a decrease in the removal capacity. Its attributed to the control of several factors. The most important of which are the effective sites on the surface of the adsorbent will remain unsaturated during the adsorption reaction. This lead to decreases in the wattage capacity of the extract with increasing the weight of the adsorbent material ${ }^{(21,22)}$. Which remain unsaturated due to an increase in the 
number of these sites by increasing the weight of the adsorbent material relative to the dye molecules that remain constant $^{(23)}$.
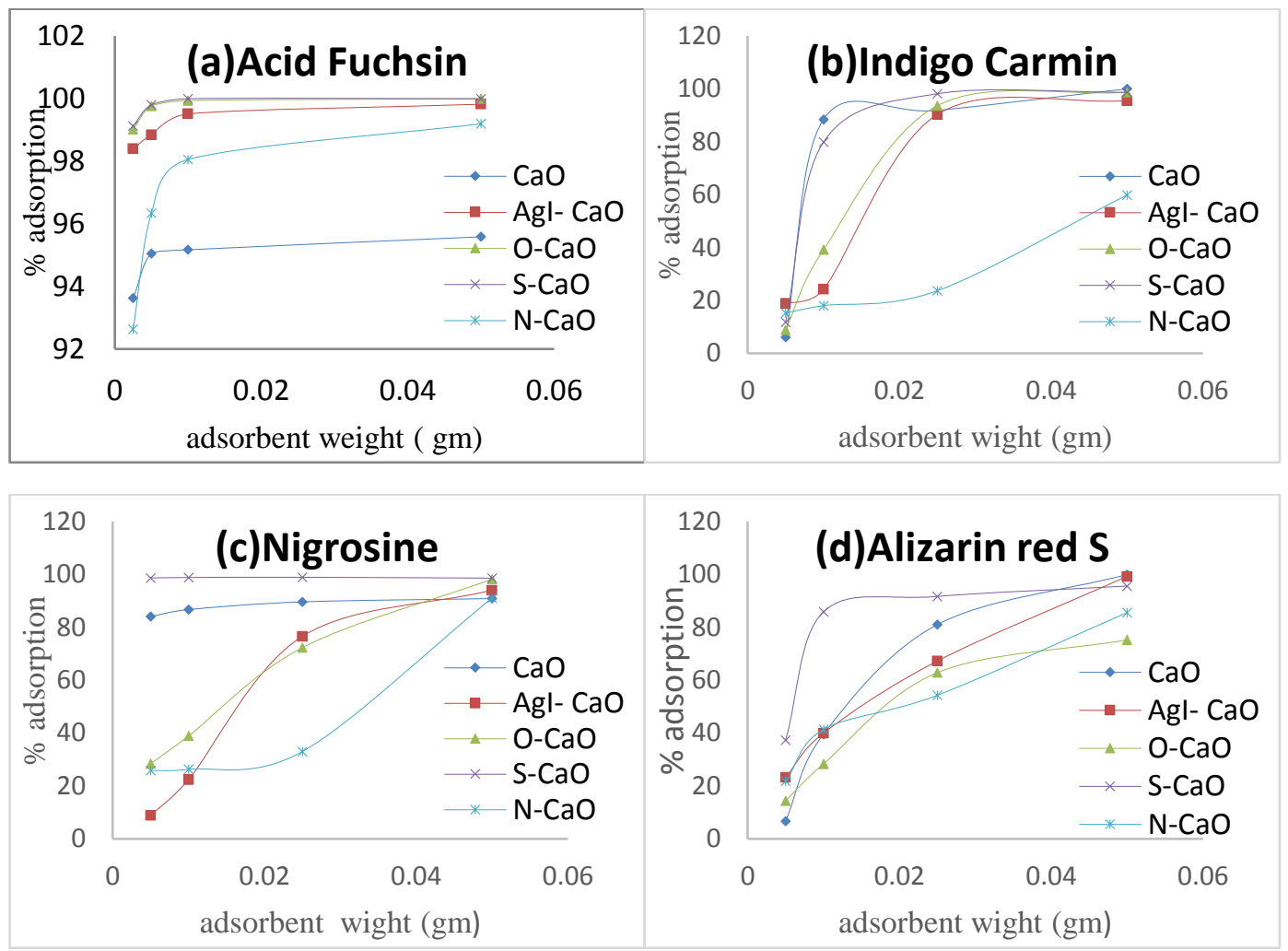

Figure 4: Relationship the Percentage of Removal for Adsorbent Weight of (a)Acid Fuchsin (b) Indigo Carmine (c) Nigrosine and (d) Alizarin red S dye

\subsection{Shaking Speed}

Figure 5 shows the influence of the shaking rate on the sorption of dyes by $\mathrm{CaO}$ and modified $\mathrm{CaO}$. The results showed that the removal percentage of dyes was enhanced with an increase the shaking speed. With the increasing of the agitation speed, the rate of diffusion of the dye molecules from the dye solution to the liquid boundary layer surrounding the adsorbent particle become higher because of an enhancement of the turbulence and a decrease of the thickness of the liquid boundary layer. Increasing agitation rate decreases the film resistance to mass transfer surrounding the sorbent particles, thus, increasing sorption of dyes molecules ${ }^{(24)}$. At higher speed the percentage removal of dyes due to the high speed may result in higher separation of the adsorbate from the surface adsorbent or to contact of the adsorbate and surface adsorbent.

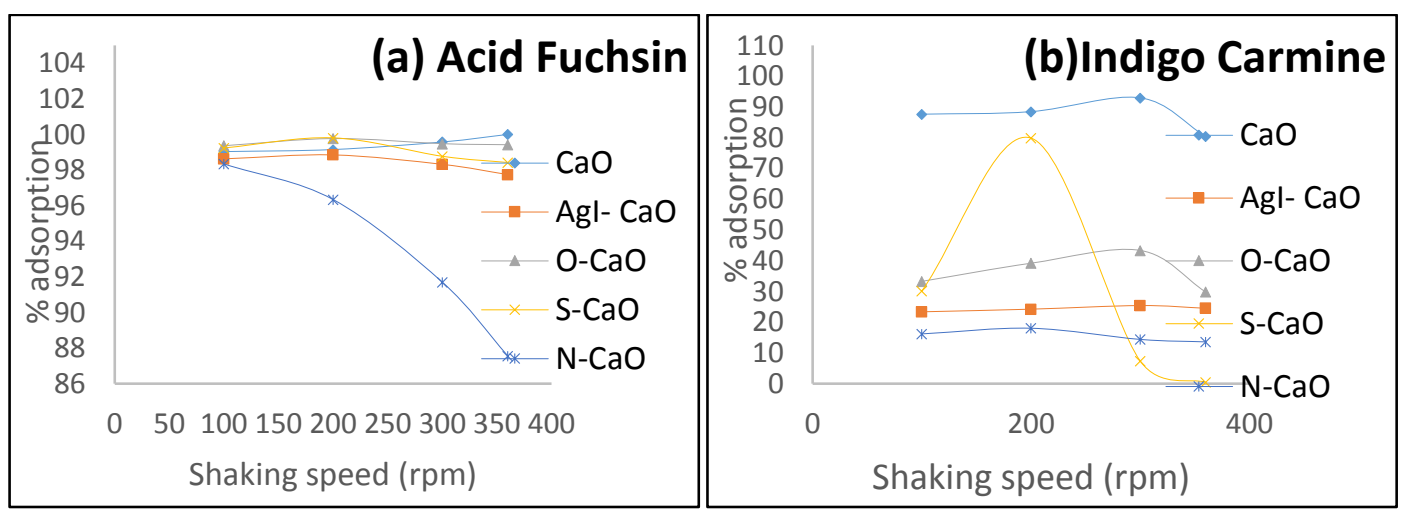




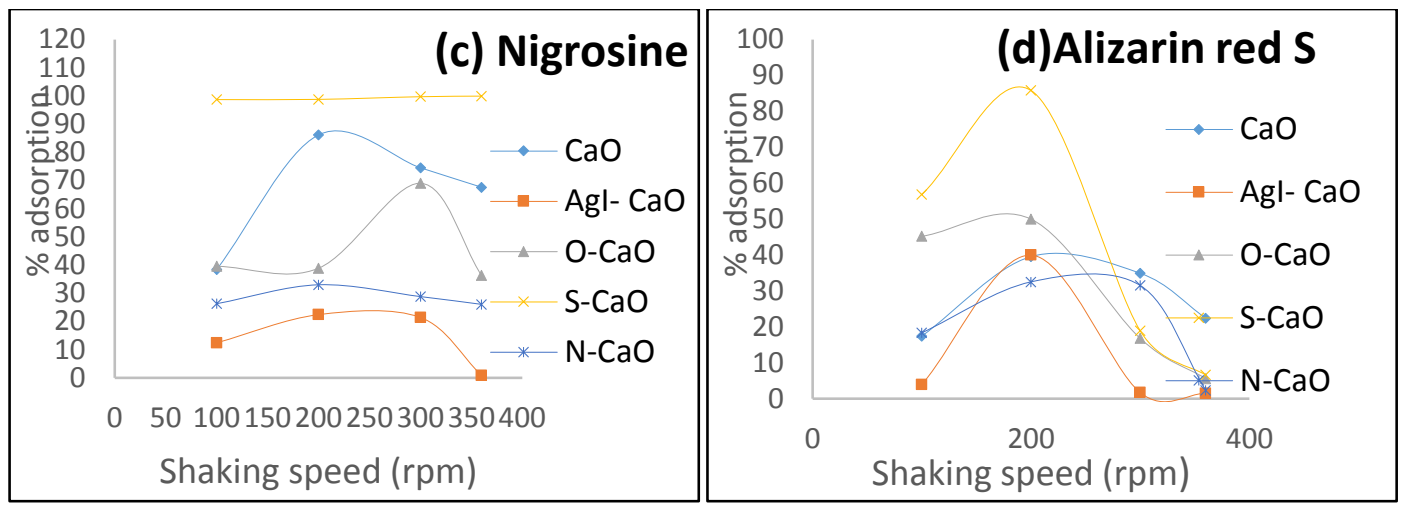

Fig.5: Relationship the percentage of removal for Shaking speed of (a)Acid Fuchsin (b) Indigo Carmine (c) Nigrosine and (d) Alizarin red S dye

\subsection{Effect of Temperature}

Figure 6 shows the effect of temperature on the sorption of dyes. The removals capacity have been increased with temperature increase, this phenomena was carried out for both $\mathrm{CaO}$ and modified $\mathrm{CaO}$, and for all dye concentration, indicating an endothermic process. The increment of adsorption may be due to the increased of the rate of diffusion of the adsorbate molecules across the surface boundary layer and by the internal pores of the adsorbent particles. An increased number of molecules may obtain sufficient energy to succumb an interaction with active sites at the surface ${ }^{(25)}$. Thus, batch mode studies were carried out at 200 rpm of shaking speed.
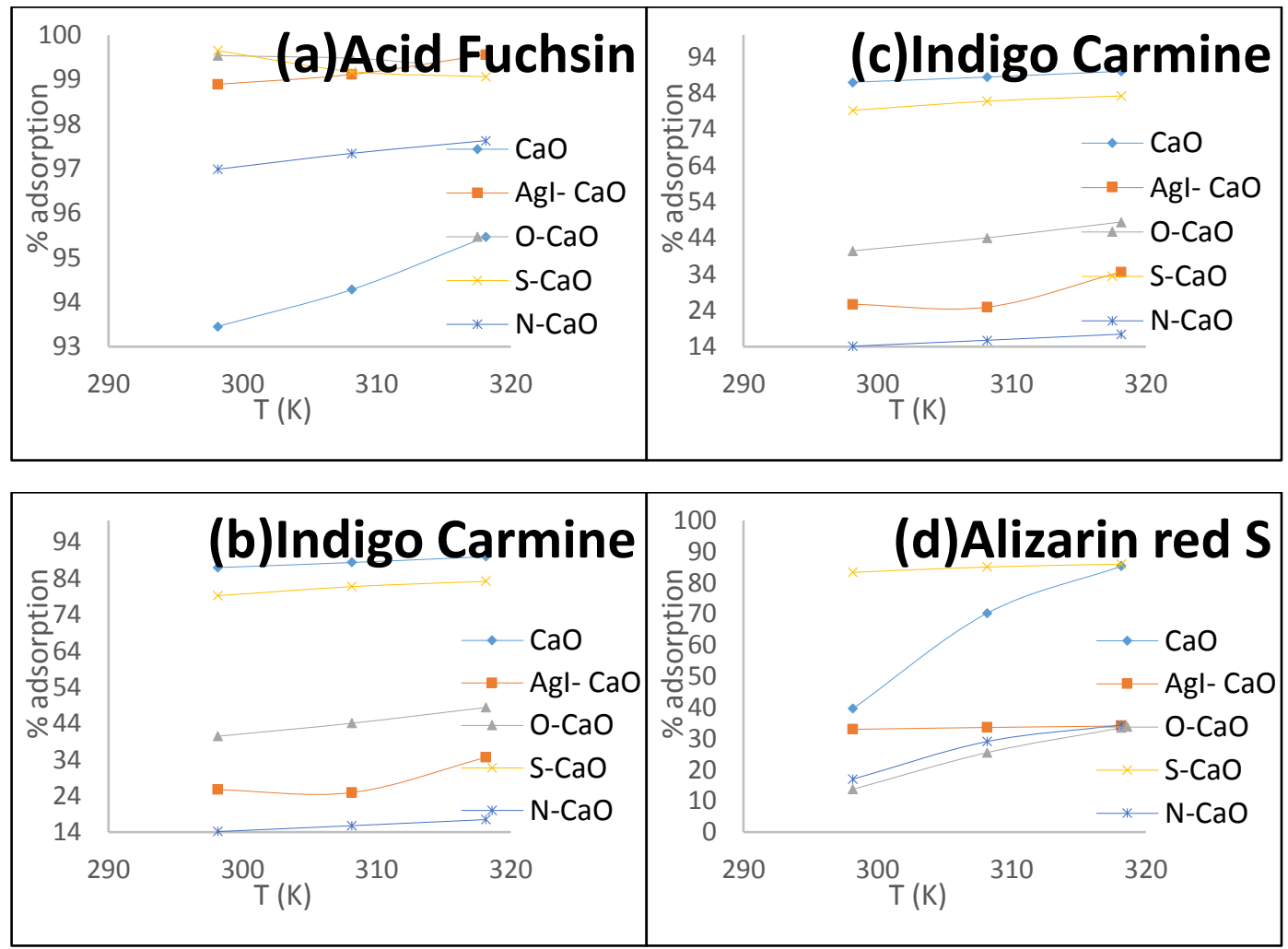

Figure 5: Relationship the percentage of removal for Temperature of (a)Acid Fuchsin (b) Indigo Carmine (c) Nigrosine and (d) Alizarin red S dye

\section{CONCLUSIONS}

The results show that $\mathrm{CaO}$ and modified $\mathrm{CaO}$ is efficient adsorbent for removal four dyes from aqueous solutions, increase the percentage of removal of dyes by increasing time, $\mathrm{pH}$, adsorbent weight, shaking speed and temperature, 
exactly dye Alizaren Red $\mathrm{S}$ decreased with increased $\mathrm{pH}$ in adsorbent $\mathrm{CaO}, \mathrm{AgI}-\mathrm{CaO}, \mathrm{O}-\mathrm{CaO}$ and $\mathrm{N}-\mathrm{CaO}$. While the percentage of removal of the dyes are less with increased Initial Concentrations.

\section{REFERENCES}

[1]. Butt H-J, Graf K, Kappl M. Physics and Chemistry of Interfaces: WILEY-VCH GmbH \& Co. KGaA; 2003.

[2]. Layla B. A., Al-Najar A.A., Zaki N. K. Physical characteristics of adsorption-desorption of Fipronil in the soil, African Journal of Engineering ResearchVol. 4, No, 2, pp 26-35, (2016).

[3]. Mohamad_abdelSalam, Ghalia Al_Zhrani, Samia A.Kosa, "Simultaneous removal of copper(II), lead(II), zinc(II) and cadmium(II) from aqueous solutions by multi-walled carbon nanotubes", Journal of Simultaneous removal of copper(II), lead(II), zinc(II) and cadmium(II) from aqueous solutions by multi-walled carbon nanotubes,vol. 15, pp.398-408, 2012.

[4]. Pragnesh_Dave, N. Subrahmanyam, and Surendra_Sharma "'Kinetics and thermodynamics of copper ions removal from aqueous solution by use of activated charcoal Indian Journal of Chemical Technology, vol. 16, pp.234-239, 2009.

[5]. Zaki N. Kadhim, Using of Isolated Hydroxyapatite from Sheep Bones to Remove Lead (II) from Aqueous Solution and Studying the Thermodynamics and Adsorption Isotherm, Asian J.Appl.Sci., vol.4, pp.149-160, 2016.

[6]. F. Daniels, J. W. Williams, P. Bender and R. A. Alberty, Experimental Physical Chemistry, (Me Graw-Hill, New York), 1962.

[7]. R. M. M. Al-Ani, "M. Sc.”, Education Ibn Al-Haitham Deparment of Chemistry, pp. 6-7, (2007).

[8]. Haifa_Jassim Sanabah Al-Hassani, "M.Sc. Thesis", College of Education For Girls Kufa University, 7, 2006.

[9]. Omaimah M.N. Al Gohary, In vitro adsorption of mebeverine hydrochloride onto kaolin and its relationship to pharmacological effects of the drug in vivo" Pharmaceutics Acta Helvetiae, vol. 72, pp.11-21, 1997.

[10]. G. Mckay, M. S. Oyrwsurn and A. G. Sweeeney, "The Removal of Colour from Effluent Using Various Adsorbent -III. Silica: Rate Processes" Water Research, vol. 14, no. 1, pp.15.20, 1980.

[11]. M. Domingo_Garcia, I. Fernandez_Morales, F. J. Lopez-Garzon, C. Moreno_Castilla, AND M. PYDA, "Effect of Oxygen Plasma Treatment on the Porosity and Surface Chemical Nature of Glassy Carbons", Journal of Colloid and Interface Science, vol. 176, pp.128-137, 1995.

[12]. Ibtighaa K. R., Mouayed H. and Zaki N . Kadhim, "Investigation of nigrosine, alizarin, indigo and acid fuchsin removal by modification of $\mathrm{CaO}$ derived from eggshell with AgI: Adsorption, kinetic and photocatalytic studies", Eur. J. Chem., ID 1820, December 26, 2018.

[13]. Osman_Gulnaz, Aysenur Kaya, Sadik Dincer, " The reuse of dried activated sludge for adsorption of reactive dye", Journal of Hazardous Materials, vol. 134, pp. 190-196, 2006.

[14]. Arzu Y. Dursun*, Ozlem Tepe, "Removal of Chemazol Reactive Red 195 from aqueous solution by dehydrated beet pulp carbon", Journal of hazardous materials, vol. 194, pp.303-311, 2011.

[15]. C. Namasivayam,* N. Muniasamy, K. Gayatri, M. Rani \& K. Ranganathan, "Removal of dyes from Aqueous Solution by Cellulosic Waste Orange Peel”, Journal of Bioresource Technology, vol. 57, pp.37-43, 1996.

[16]. C. Namasivayam CI, R. T. Yamuna, "Adsorption of direct red 12 B by biogas residual slurry: equilibrium and rate processes", Journal of Environmental Pollution, vol. 89, pp.1-7, 1995.

[17]. V. Belessi, D. Lambropoulou, I. Konstantinou, R. Zboril, J. Tucek, D. Jancik, T. Albanis c, D. Petridis a, "Structure and photocatalytic performance of magnetically separable titania photocatalysts for the degradation of propachlor", Applied Catalysis B: Environmental, vol. 87, pp. 181-189, 2009.

[18]. Jianwei Fu, Zhonghui Chen, Minghuan Wang, Shujun Liu, Jinghui Zhang, Jianan Zhang, Runping Han b , Qun $\mathrm{Xu}$, "Adsorption of methylene blue by a high-efficiency adsorbent (polydopamine microspheres): Kinetics, isotherm, thermodynamics and mechanism analysis", Chemical Engineering Journal, vol. 259, pp.53-61, 2015.

[19]. Kyriakos Bourikas, Maria Stylidi, Dimitris I. Kondarides, and Xenophon E. Verykios, "Adsorption of Acid Orange 7 on the Surface of Titanium Dioxide", Chem. Eng. J, vol. 21, pp. 9222-9230, 2005.

[20]. Paritam K. Dutta, Ajay K. Ray, Virender K. Sharma, Frank J. Millero, "Adsorption of arsenate and arsenite on titanium dioxide suspensions", Journal of Colloid and Interface Science, vol. 278, pp. 270-275, 2004.

[21]. R. Batmaz.,"M.Sc. Thesis", University of Waterloo, Ontario, Canada, 2013.

[22]. Runping Han, Weihua Zou, Zongpei Zhang, Jie Shi, Jiujun Yang, "Removal of copper(II) and lead(II) from aqueous solution by manganese oxide coated sand I. Characterization and kinetic study", Journal of Hazardous Materials, vol. 137, pp. 384-395, 2006.

[23]. Hsu, Yung-Chien, Chun-Chiao Chiang, and Mei-Feng Yu, "Adsorption behavior of basic dyes on activated clay", Separation science and technology, vol. 32, no. 15, pp. 2513-2534, 1997.

[24]. Patil, S., Patil, J., Renukdas, Satish, and Patil, N, "Mechanism Of Adsorption Of Ferrous Ions From Waste Water On Natural Adsorbents", World Journal of Pharmacy and Pharmaceutical Sciences, vol. 4, no. 7, pp. 767-788, 2015.

[25]. Yasemin O" zdemir, Mehmet Dog an, Mahir Alkan, "Adsorption of cationic dyes from aqueous solutions by sepiolite", Journal of Microporous and Mesoporous Materials,vol. 96, pp.419-427, 2006. 